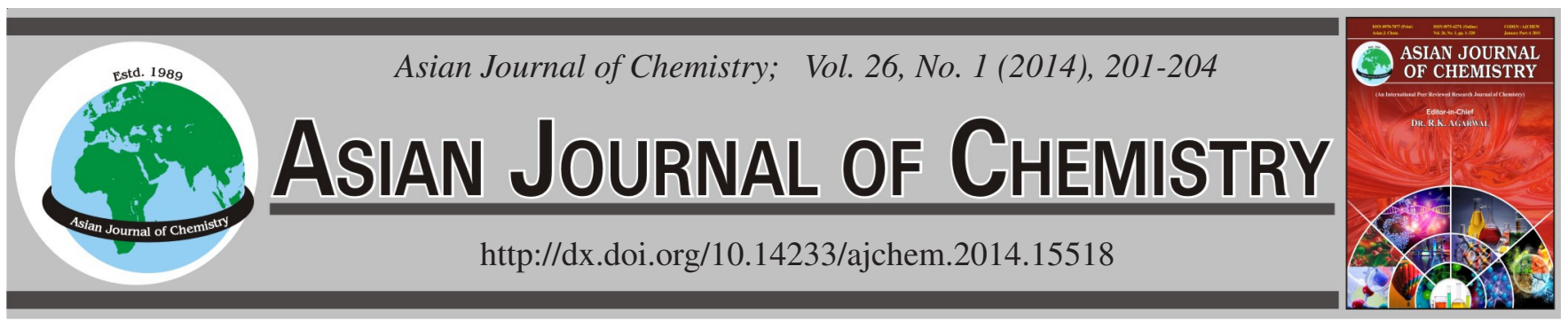

\title{
Inhibitory Activity of the Extract from Broussonetia papyrifera Fruits to Cellular Lipid Peroxidation in vitro
}

\author{
Yang $\operatorname{Li}^{1}$, Xiaoya Shang ${ }^{1}$, Weining Niu ${ }^{1}$, Chunlan Xu ${ }^{1}$ and Chuanguang Qin ${ }^{1,2, *}$
}

${ }^{1}$ School of Life Sciences, Northwestern Polytechnical University, Xi'an 710072, P.R. China

${ }^{2}$ Key Laboratory on Space Applied Physics and Chemistry of Ministry of Education; Key Laboratory on Macromolecular Science \& Technology of Shaanxi Province, Department of Applied Chemistry, School of Natural and Applied Sciences, Northwestern Polytechnical University, Xi'an, 710129 P.R. China

*Corresponding author: Fax: +86 29 88460332; Tel: +86 13991392191; E-mail: qinchg@nwpu.edu.cn

\begin{abstract}
On the basis of our previous work on the antioxidant and anticancer activities of the extract of the Broussonetia papyrifera fruits, in vitro inhibitory activity of the extract to cellular lipid peroxidation was under study in present work. Inhibitory activity of the extract was evaluated by determining the ability to inhibit $\mathrm{H}_{2} \mathrm{O}_{2}$-induced erythrocyte hemolysis and lipid peroxidation of liver homogenate, to inhibit mitochondrial swelling and to scavenge hydroxyl radical. The total flavonoid content was found to be $75.46 \pm 1.91 \mathrm{mg}$ rutin equivalents $\mathrm{g}^{-1}$ lyophilized extract. The extract was a potent inhibitor of erythrocyte hemolysis, lipid peroxidation and mitochondrial swelling and was a scavenger of hydroxyl radical. The inhibitory activity of the extract showed a dose-dependent increase in the assays. This study suggested the extract was a potent antioxidant and might be developed as a potential botanical medicine or functional food.
\end{abstract}

Keywords: Broussonetia papyrifera fruit, Ethanolic extract, Lipid peroxidation, Antioxidant activity, Flavonoid compound.

\section{INTRODUCTION}

Reactive oxygen species (ROS) are generated during normal metabolism in the human body, which could attack various biomolecules including proteins, lipoproteins, lipids and DNA readily to induce oxidative damage. It is believed that several chronic human diseases, including cardiovascular diseases, rheumatism, diabetes mellitus and cancer, have a very close relationship with oxidative damage ${ }^{1}$. Therefore, the usefulness of antioxidants in protection against these diseases captures the attention.

Numerous natural antioxidants have already been isolated from plants such as fruits, vegetables, seeds and roots. The phenolic compounds, comprising at least 8000 different known structures including simple phenols, phenolic acids, flavonoids, are the important ones ${ }^{2}$. It has been stated that phenolic compounds are multifunctional antioxidants acting as scavenging free radicals ${ }^{3}$, reducing agents ${ }^{4}$, hydrogen-donating antioxidants $^{5}$ and improving the endogenous antioxidant system ${ }^{6}$. The phenolic compounds could also influence cellular oxidation and reduction environment to regulate proliferation and/or be a novel redox drug for cancer ${ }^{7,8}$. Therefore, as development activity increases in this area, it is not surprising that phenolic compounds have gained tremendous interest.
Broussonetia papyrifera (Moraceae) grows naturally in Pacific countries such as China, Burma, Polynesia and USA? The fruits, barks and roots are all used in traditional Chinese medicines. For example, the fruits have been used for treatment of ophthalmic and Alzheimer's disease in Chinese folk ${ }^{10,11}$. The compounds extracted from different parts of Broussonetia papyrifera have been extensively studied and shown to inhibit PTP1B enzyme ${ }^{12}$ and lipid peroxidation ${ }^{13}$, antihyperglycemic ${ }^{14}$ and antihepatotoxic ${ }^{15}$. However, study of ethanolic extract from the fruits has been limited.

According to our previous investigation, the extract had antioxidant activity and could inhibit cancer cells proliferation ${ }^{16}$. Therefore, the objective of this study was to investigate inhibitory activity of the extract to cellular lipid peroxidation in vitro. This work has provided some valuable data for future study of the extract.

\section{EXPERIMENTAL}

Fresh Broussonetia papyrifera fruits were collected from Beilin district of Xi' an, China during July 2011 and identified at the School of Life Sciences, Northwestern Polytechnical University. A voucher specimen is preserved in the same place. The fruits were placed in polyethylene bags and stored at $-20{ }^{\circ} \mathrm{C}$ until use. 
Preparation of the extract: Broussonetia papyrifera fruits were extracted at $40{ }^{\circ} \mathrm{C}$ in $80 \%$ ethanol for $2 \mathrm{~h}$. The extract was filtered through filter paper and evaporated at $40{ }^{\circ} \mathrm{C}$ in rotary evaporator (EYELA, N1001, Japan). Subsequently, the concentrated solution was passed through a $2 \mathrm{~g}$ sorbent weight $\mathrm{C}_{18}$ SPE cartridge (AGELA, China), previously activated with methanol followed by deionized water. $10 \mathrm{~mL}$ of deionized water and ethyl acetate were used to wash the SPE cartridge and then the extract was eluted with methanol. The extract was dried by rotary evaporator at $40^{\circ} \mathrm{C}$, redissolved in deionized water and then lyophilized in a lyophilizer (CHRIST, Alpha 1-2, Germany). The extract was placed in a plastic bottle and stored at room temperature.

Determination of total flavonoid content: Total flavonoid content was determined according to the aluminum chloride colorimetric method ${ }^{17}$. Briefly, $1 \mathrm{~mL}$ of $1.6 \mathrm{mg} \mathrm{mL}^{-1}$ the extract was placed in a $10 \mathrm{~mL}$ volumetric flask and $0.4 \mathrm{~mL}$ of $5 \%$ sodium nitrite was added. After $6 \mathrm{~min}, 0.4 \mathrm{~mL}$ of $10 \%$ aluminum chloride was added. $4 \mathrm{~mL}$ of $4 \%$ sodium hydroxide and $4.2 \mathrm{~mL}$ of $60 \%$ ethanol were added after $6 \mathrm{~min}$. The solution was mixed well and incubated for $15 \mathrm{~min}$ at room temperature and then the absorbance was measured at $510 \mathrm{~nm}$ by a UVvisible spectrophotometer (HITACHI, F2300, Japan). The measurement was compared to a standard curve of rutin and expressed as milligram rutin equivalents (RE) $\mathrm{g}^{-1}$ lyophilized extract.

Preparation of erythrocytes and liver homogenate: Kunming mice, body weight of 18-22 g, were purchased from the Experimental Animal Center of College of Medicine, Xi' an Jiaotong University. The mice were housed in polypropylene cages and given standard food and water ad libitum. After the blood was collected by enucleating eyes in heparinized tubes, the mice were sacrificed by cervical dislocation and the liver was excised quickly. Erythrocytes were isolated and stored according to the method of Yuan et al. ${ }^{18}$ and Yang et al. ${ }^{19}$ with some modifications. Blood samples were washed three times by centrifugation ( $2000 \mathrm{rpm}, 5 \mathrm{~min}$ ) in 10 volumes of phosphate buffer saline (PBS: $150 \mathrm{mmol} \mathrm{L}^{-1} \mathrm{NaCl}, 8.1 \mathrm{mmol} \mathrm{L}^{-1} \mathrm{Na}_{2} \mathrm{HPO}_{4}$, 1.9 mmol L ${ }^{-1} \mathrm{NaH}_{2} \mathrm{PO}_{4}, 10 \mathrm{mmol} \mathrm{L}{ }^{-1}$ EDTA, pH 7.4). The supernatant and buffy coats were carefully removed after each centrifugation and then the compacted erythrocytes were obtained. The erythrocytes were stored at $4{ }^{\circ} \mathrm{C}$ and used within $6 \mathrm{~h}$.

On the other hand, the liver was washed, weighed and then homogenized with ice-cold PBS in an ice bath to yield a $10 \%$ (w/v) homogenate by means of a Potter-Elvehjem homogenizer. The liver homogenate was stored at $4{ }^{\circ} \mathrm{C}$.

Inhibition of erythrocyte hemolysis: The inhibition of erythrocyte hemolysis was determined according to the method of Tedesco et al. ${ }^{20}$ with some modifications. To $1 \mathrm{~mL}$ of $0.5 \%$ $(\mathrm{v} / \mathrm{v})$ suspension of erythrocytes in PBS, $0.1 \mathrm{~mL}$ of the extract at different concentrations and $0.1 \mathrm{~mL}$ of $100 \mathrm{mmol} \mathrm{L}^{-1} \mathrm{H}_{2} \mathrm{O}_{2}$ were added. The mixture was incubated in water bath at $37^{\circ} \mathrm{C}$ for $1 \mathrm{~h}$. After that, $4 \mathrm{~mL}$ PBS was added to the mixture and centrifuged at $2000 \mathrm{rpm}$ for $5 \mathrm{~min}$. The absorbance of the supernatant was measured at $415 \mathrm{~nm}$ to determine the hemolysis. The inhibitory effect of the extract was compared with positive control of ascorbic acid. The inhibitive rate of hemolysis was calculated as follows:

$$
\text { Inhibition }(\%)=\frac{\left[\mathrm{A}_{415(\text { Control })}-\mathrm{A}_{415(\text { Sample })}\right]}{\mathrm{A}_{415(\text { Control })}} \times 100 \%
$$

The hemolysis induced by the extract was also evaluated. As described above, erythrocytes and $10 \mu \mathrm{g}$ of the extract were incubated at $37^{\circ} \mathrm{C}$ for $1 \mathrm{~h}$ and the absorbance was measured.

Lipid peroxidation inhibitory activity: Lipid peroxidation was determined by the measurement of malondialdehyde (MDA) according to the method of Ohkawa et al. ${ }^{21}$ with slight modifications. $0.2 \mathrm{~mL}$ of $10 \%$ liver homogenate and $0.1 \mathrm{~mL}$ of the extract at different concentrations were mixed and then treated with $0.1 \mathrm{~mL}$ of $100 \mathrm{mmol} \mathrm{L}^{-1} \mathrm{H}_{2} \mathrm{O}_{2}$ at $37^{\circ} \mathrm{C}$ for $1 \mathrm{~h}$. Subsequently, the mixture was combined with $0.2 \mathrm{~mL}$ of $8.1 \%$ SDS, $1.5 \mathrm{~mL}$ of $15 \%$ trichloroacetic acid and $1.5 \mathrm{~mL}$ of $0.8 \%$ thiobarbituric acid. The mixture was heated to $95^{\circ} \mathrm{C}$ for $1 \mathrm{~h}$. After cooling in an ice bath, the mixture was centrifuged at $3000 \mathrm{rpm}$ for $10 \mathrm{~min}$. The absorbance of the supernatant fraction was measured at $532 \mathrm{~nm}$ on a spectrophotometer. Rutin was used as positive control. The inhibition of lipid peroxidation was calculated using the following formula:

$$
\text { Inhibition }(\%)=\frac{\left[\mathrm{A}_{532(\text { Control })}-\mathrm{A}_{532 \text { (Sample) }}\right]}{\mathrm{A}_{532(\text { Control })}} \times 100 \%
$$

Mitochondrial swelling assay: Mitochondrial swelling assay was performed according to the procedures described by Song et al. ${ }^{22}$. The liver homogenate was centrifuged at 1000 $\mathrm{rpm}$ at $4^{\circ} \mathrm{C}$ for $20 \mathrm{~min}$ and then the mitochondria were isolated by centrifugation of the supernatant at $10000 \mathrm{rpm}$ at $4{ }^{\circ} \mathrm{C}$ for $20 \mathrm{~min}$. The pellet was washed with ice-cold PBS by centrifuged at $10000 \mathrm{rpm}$ at $4{ }^{\circ} \mathrm{C}$ for $20 \mathrm{~min}$. The mitochondria were resuspended in ice-cold PBS to a concentration of 0.5 $\mathrm{mg} \mathrm{mL}^{-1}$ of protein by following the Bradford method, using BSA as standard and stored at $4^{\circ} \mathrm{C}$. To a mixture of $0.2 \mathrm{~mL}$ of the extract at different concentrations and $2 \mathrm{~mL}$ of mitochondrial suspension, $0.2 \mathrm{~mL}$ of $0.5 \mathrm{mmol} \mathrm{L}^{-1}$ ferrous sulfate and 0.2 $\mathrm{mL}$ of $0.5 \mathrm{mmol} \mathrm{L} \mathrm{L}^{-1}$ ascorbic acid were added. The mixture was then incubated at $37^{\circ} \mathrm{C}$ and the absorbance of the mixture was measured at $520 \mathrm{~nm}$ at intervals. A decrease of the absorbance indicates an increase of mitochondrial swelling. PBS was used instead of the extract, ferrous sulfate and ascorbic acid in the control group.

Hydroxyl radical scavenging assay: The assay was determined using the methods of Wang et al. ${ }^{23}$ with some modifications. The $\mathrm{OH}^{\bullet}$ in aqueous media is generated through the Fenton reaction. To a $1.5 \mathrm{~mL}$ tube, $67 \mu \mathrm{L}$ of $2.2 \mathrm{mmol} \mathrm{L}^{-1}$ $\mathrm{H}_{2} \mathrm{O}_{2}, 67 \mu \mathrm{L}$ of $2.25 \mathrm{mmol} \mathrm{L}^{-1}$ salicyclic acid, $67 \mu \mathrm{L}$ of 2.25 $\mathrm{mmol} \mathrm{L}^{-1} \mathrm{FeSO}_{4}$ and $0.1 \mathrm{~mL}$ of the extract at different concentrations were added, mixed and stood for 5 min in the dark at room temperature. The absorbance was measured at $510 \mathrm{~nm}$. Ascorbic acid was used as positive control. The free radical scavenging activity was calculated as follows:

$$
\text { Inhibition }(\%)=\frac{\left[\mathrm{A}_{510(\text { Control })}-\mathrm{A}_{510(\text { Sample })}\right]}{\mathrm{A}_{510(\text { Control })}} \times 100 \%
$$

Statistical analysis: Results were expressed as the mean \pm SD of three independent experiments. Differences between sample group and control group were analyzed with One-way ANOVA procedures (Prism 5, GraphPad Software, USA). A value of $p<0.05$ was regarded as being significant. $\mathrm{IC}_{50}$ values were calculated by regression analysis. 
RESULTS AND DISCUSSION

Ethanolic extract of Broussonetia papyrifera fruits: As described above, the extract was purified by washing the $\mathrm{C}_{18}$ cartridge and the sugars, acids and other water soluble compounds were removed. The extract was the pigment of fresh Broussonetia papyrifera fruit and showed orange colour. By phytochemical screening, it was found that the extract contained flavonoids. This may be the reason for its antioxidant activity. The total flavonoid content was $75.46 \pm 1.91 \mathrm{mg}$ rutin equivalent $\mathrm{g}^{-1}$ lyophilized extract, which was higher than that of mulberry leaves of 19 varieties of species ${ }^{17}$.

Inhibition of erythrocyte hemolysis: Because of the high concentration of polyunsaturated fatty acids in the membrane and the $\mathrm{O}_{2}$ transport associated with redox active hemoglobin molecules, which are potent promoters of ROS, erythrocytes are considered as prime targets for free radical attack ${ }^{24}$. Therefore, erythrocytes have been used as a cellular model to investigate oxidative damage in biomembranes.

Hemolysis of erythrocytes induced by the extract was determined. The percentage of hemolysis was found at $4.11 \pm$ $0.35 \%$, which was not significantly different from control of $3.91 \pm 0.53 \%$. This result showed the extract had no harmful effect on erythrocytes.

The inhibitory effect of the extract on erythrocyte hemolysis was evaluated by oxidative stress induced by $\mathrm{H}_{2} \mathrm{O}_{2}$. Fig. 1 showed that lysis of erythrocytes caused by $\mathrm{H}_{2} \mathrm{O}_{2}$ was significantly inhibited by the extract. The inhibitory activity to erythrocyte hemolysis was dose-dependent over the range of tested concentrations. The $\mathrm{IC}_{50}$ value of the extract was $12.84 \mu \mathrm{g}$ $\mathrm{mL}^{-1}$, which was lower than that of positive control $(31.77 \mu \mathrm{g}$ $\left.\mathrm{mL}^{-1}\right)$. The results indicated the extract could provide stronger protection for erythrocytes against damage caused by $\mathrm{H}_{2} \mathrm{O}_{2}$ than ascorbic acid.

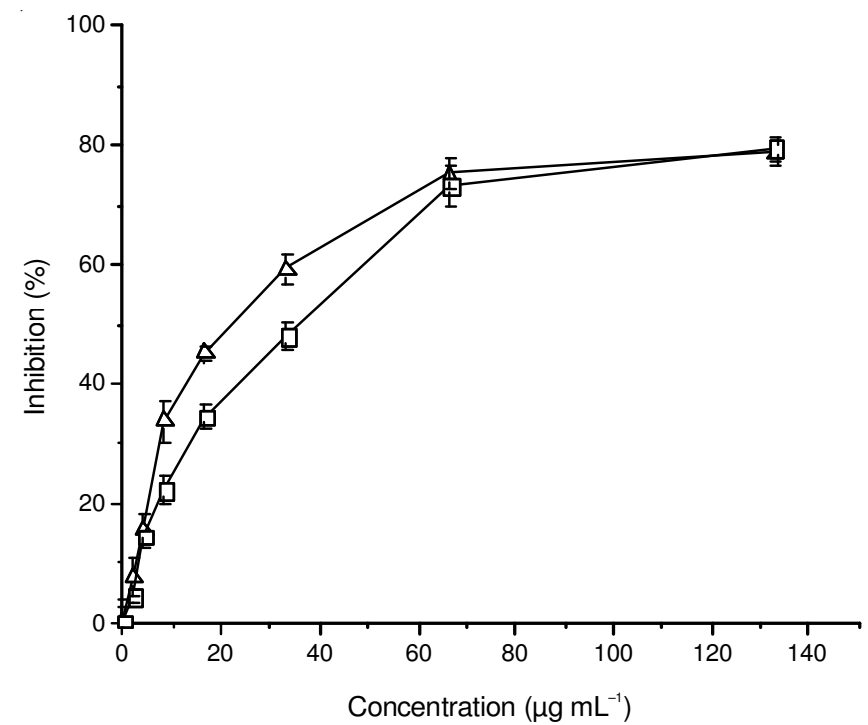

Fig. 1. Inhibition of Broussonetia papyrifera fruit extract against $\mathrm{H}_{2} \mathrm{O}_{2}$ induced erythrocyte hemolysis. Data is expressed as mean $\pm \mathrm{SD}$ $(\mathrm{n}=3)$. Values in different groups are significantly different from control, $p<0.05$. $(\Delta)$ Broussonetia papyrifera fruit extract; ascorbic acid

Inhibitory activity to lipid peroxidation: Lipid peroxidation is an oxidative alteration of polyunsaturated fatty acids, which is a common process in the biological systems. Malondialdehyde one of the major products of lipid peroxidation, has been extensively used as an index of lipid peroxidation and as a marker of oxidative stress ${ }^{25}$. The measure of malondialdehyde formation has been widely used for determination of anti-lipid peroxidation activity of natural extracts.

Compared to the control, addition of $\mathrm{H}_{2} \mathrm{O}_{2}$ to the liver homogenate for $1 \mathrm{~h}$ significantly increased malondialdehyde formation. However, the extract $\left(12.5-400 \mu \mathrm{g} \mathrm{mL}^{-1}\right)$ added to the reaction system significantly reduced malondialdehyde formation, indicating significant anti-lipid peroxidation activity. Fig. 2 showed that inhibition of lipid peroxidation increased with increasing concentrations of the extract. The $\mathrm{IC}_{50}$ value of the extract for lipid peroxidation inhibition on liver homogenate was $155.7 \mu \mathrm{g} \mathrm{mL}^{-1}$, which seemed to have roughly the same inhibitory effect as rutin $\left(147 \mu \mathrm{g} \mathrm{mL}^{-1}\right)$.

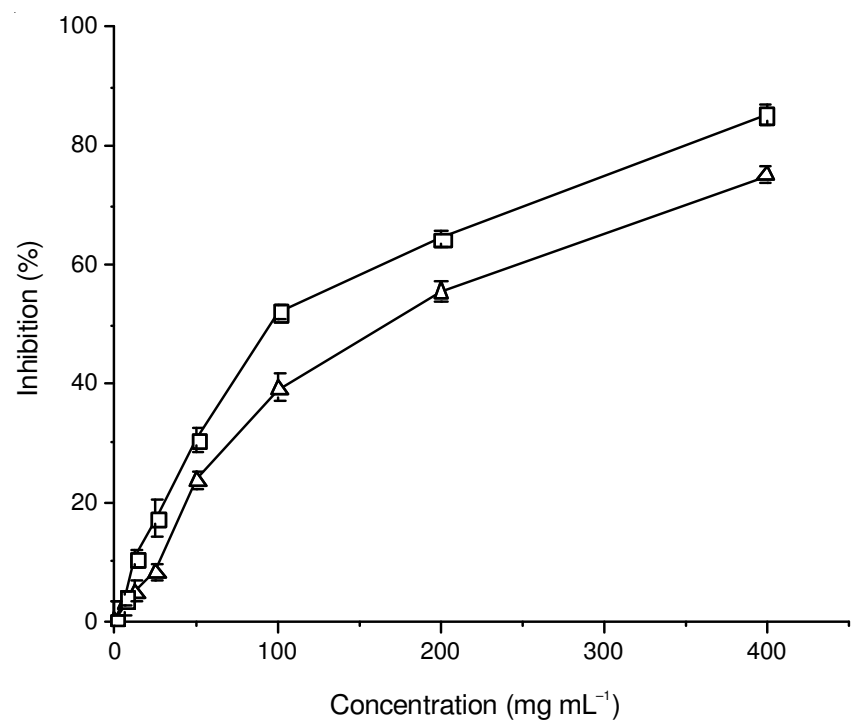

Fig. 2. Inhibitory activity of Broussonetia papyrifera fruit extract to lipid peroxidation. Data is expressed as mean $\pm \mathrm{SD}(\mathrm{n}=3)$. Values of samples at $12.5-400 \mu \mathrm{g} \mathrm{mL}^{-1}$ in different groups are significantly different from control, $p<0.05$. ( $\Delta$ ) Broussonetia papyrifera fruit extract; ( $\square$ ) rutin

Inhibitory effect on mitochondrial swelling: Reaction system of ferrous sulfate and ascorbic acid produced $\mathrm{H}_{2} \mathrm{O}_{2}$ to initiate lipid peroxidation and destroy the structure of mitochondrial membrane, which was the reason for mitochondrial swelling ${ }^{26}$. The results were shown in Fig. 3. A decrease of absorbance at $520 \mathrm{~nm}$ represented the swelling of mitochondrial increased and the integrity of mitochondrial was damaged. Compared to the control group, absorbance of damage groups (with ferrous sulfate and ascorbic acid) decreased considerably with time. However, the swelling of mitochondrial decreased present in the extract. This result indicated the extract inhibited mitochondrial swelling and the inhibitory activity to mitochondrial swelling increased as the concentration increased. Rutin showed stronger inhibitory effect than that of the extract at the same concentration of $200 \mu \mathrm{g} \mathrm{mL} \mathrm{m}^{-1}$.

Hydroxyl radical scavenging activity: Hydroxyl radical, known to be the most biologically active free radical, is a major ROS in living organisms and is being continuously formed in a process of reduction of oxygen to water ${ }^{2}$. It can attack and 


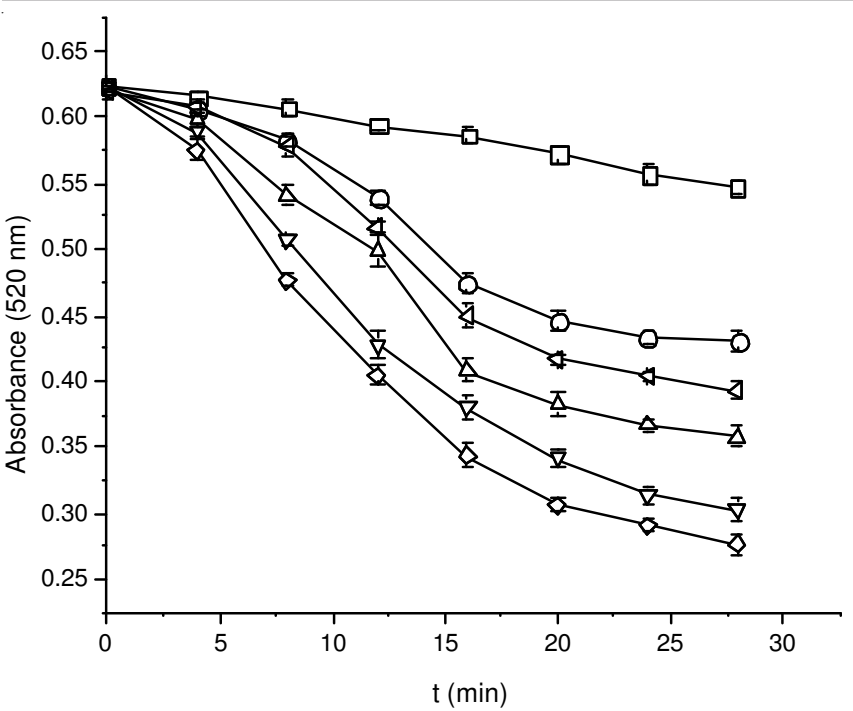

Fig. 3. Inhibitory effect of Broussonetia papyrifera fruit extract on mitochondrial swelling. Data is expressed as mean \pm SD $(n=3)$. Values in different groups are significantly different from damage group, $p<0.05$. ( $\square)$ control group; $(\diamond)$ damage group; $(\nabla) 50$ $\mu \mathrm{g} \cdot \mathrm{mL}^{-1}$ of the extract; $(\Delta) 200 \mu \mathrm{g} \mathrm{mL} \mathrm{mL}^{-1}$ of the extract; (O) $800 \mu \mathrm{g}$ $\mathrm{mL}^{-1}$ of the extract; $(\triangleleft) 200 \mu \mathrm{g} \mathrm{mL} \mathrm{m}^{-1}$ of rutin

damage virtually any molecule including macromolecules such as DNA, proteins, membrane lipids and carbohydrates ${ }^{27}$. According to the results obtained above, the extract could inhibit $\mathrm{H}_{2} \mathrm{O}_{2}$-induced cellular lipid peroxidation. Thus, we conjectured the extract had the ability of scavenging hydroxyl radical. In this assay, the extract was evaluated for this ability. As shown in Fig. 4, a concentration dependent inhibition was observed. At final concentration of $750 \mu \mathrm{g} \mathrm{mL}^{-1}$, the scavenging ability of the extract was $86.23 \pm 0.02 \%$. The extract exhibited low $\mathrm{IC}_{50}$ value of $725.1 \mu \mathrm{g} \mathrm{mL}^{-1}$ as compared to ascorbic acid at $1640.9 \mu \mathrm{g} \mathrm{mL} \mathrm{m}^{-1}$. The scavenging activity of the extract compared with the positive control suggested that the extract was a greater potent scavenger of hydroxyl radical than ascorbic acid.

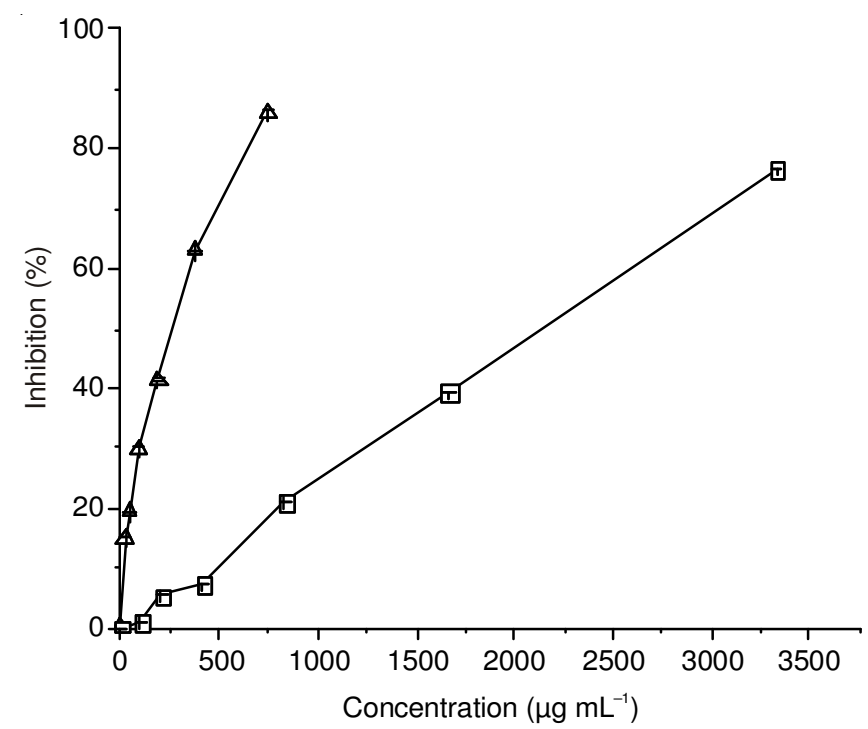

Fig. 4. Hydroxyl radical scavenging activity of Broussonetia papyrifera fruit extract. Data is expressed as mean \pm SD $(n=3)$. Values in different groups are significantly different from control, $p<0.05$. $(\Delta)$ Broussonetia papyrifera fruit extract; $(\square)$ ascorbic acid

\section{Conclusion}

This study demonstrated that the extract from Broussonetia papyrifera fruits had inhibitory activity to cellular lipid peroxidation. As an antioxidant, the isolation and characterization of the active compounds and the determination of biological activity in vivo must be processed continuously. In addition to being a potential botanical medicine, the extract can also be developed to functional food in the future due to its properties of beautiful colour, edible and antioxidant activity.

\section{ACKNOWLEDGEMENTS}

This work was financially supported by the National Natural Science Foundation of China (31001012, 31101304, 20802057, 20672086) and the Natural Science Basic Research Plan in Shaanxi Province of China (2012JZ2002).

\section{REFERENCES}

1. K. Pong, Expert Opin. Biol. Ther, 3, 127 (2003).

2. B. Lipinski, Oxid. Med. Cell Longev., 2011, 809696 (2011).

3. J. Bhagat, R. Lobo, V. Parmar and M. Ballal, Chin. J. Nat. Med., 9, 456 (2011).

4. S. Arabshahi-Delouee and A. Urooj, Food Chem., 102, 1233 (2007).

5. C.A. Rice-Evans, N.J. Miller and G. Paganga, Free Radic. Biol. Med., 20, 933 (1996).

6. H.F. Al-Azzawie and M.S. Alhamdani, Life Sci., 78, 1371 (2006).

7. E.H. Sarsour, M.G. Kumar, L. Chaudhuri, A.L. Kalen and P.C. Goswami, Antioxid. Redox Signal., 11, 2985 (2009).

8. G.T. Wondrak, Antioxid. Redox Signal., 11, 3013 (2009).

9. D. Seelenfreund, R. Pina, K.Y. Ho, S. Lobos, X. Moncada and A. Seelenfreund, New Zeal. J. Bot., 49, 413 (2011).

10. H. Matsuda, H. Cai, M. Kubo, H. Tosa and M. Inuma, Biol. Pharm. Bull., 18, 463 (1995).

11. R.Q. Mei, Y.H. Wang, G.H. Du, G.M. Liu, L. Zhang and Y.X. Cheng, J. Nat. Prod., 72, 621 (2009).

12. R.M. Chen, L.H. Hu, T.Y. An, J. Li and Q. Shen, Bioorg. Med. Chem. Lett., 12, 3387 (2002).

13. H.H. Ko, S.M. Yu, F.N. Ko, C.M. Teng and C.N. Lin, J. Nat. Prod., 60, 1008 (1997).

14. J.Y. Cha, Y.T. Kim, H.S. Kim and Y.S. Cho, J. Med. Food, 11, 499 (2008).

15. S.Y. Kim, J.H. Kim, S.K. Kim, M.J. Oh and M.Y. Jung, J. Am. Oil Chem. Soc., 71, 633 (1994).

16. Y. Li, H.L. Li, Y. Zhang, L. Li and C.G. Qin, Asian J. Chem., 25, 5453 (2013).

17. J. Zhishen, T. Mengcheng and W. Jianming, Food Chem., 64, 555 (1999).

18. X.P. Yuan, J. Wang, H.Y. Yao and F. Chen, LWT-Food Sci. Technol., 38, 877 (2005).

19. H.L. Yang, S.C. Chen, N.W. Chang, J.M. Chang, M.L. Lee, P.C. Tsai, H.H. Fu, W.W. Kao, H.C. Chiang, H.H. Wang and Y.C. Hseu, Food Chem. Toxicol., 44, 1513 (2006).

20. I. Tedesco, M. Russo, P. Russo, G. Iacomino, G.L. Russo, A. Carraturo, C. Faruolo, L. Moio and R. Palumbo, J. Nutr. Biochem., 11, 114 (2000).

21. H. Ohkawa, N. Ohishi and K. Yagi, Anal. Biochem., 95, 351 (1979).

22. YY.N. Song, J. Hui, W. Kou, R. Xin, F. Jia, N. Wang, F.Q. Hu, H.L. Zhang and H.S. Liu, Curr. Microbiol., 57, 454 (2008).

23. S.Y. Wang and H.J. Jiao, J. Agric. Food Chem., 48, 5677 (2000).

24. S.M. Sadrzadeh, E. Graf, S.S. Panter, P.E. Hallaway and J.W. Eaton, J. Biol. Chem., 259, 14354 (1984).

25. D.R. Janero, Free Radic. Biol. Med., 9, 515 (1990).

26. Z.B. Chen, J. Lv, F. Chen and L. Lin, J. Mol. Catal. B: Enzym., 55, 99 (2008).

27. B. Halliwell, Adv. Pharmacol., 38, 3 (1997). 